\title{
ANEURYSM OF THE MITRAL VALVE IN SUBACUTE BACTERIAL ENDOCARDITIS
}

\author{
BY \\ NEIL MACLEAN AND MARY K. MACDONALD \\ From the Department of Pathology, University of Edinburgh \\ Received February 28, 1957
}

The commonest form of cardiac valvular aneurysm is the thrombo-aneurysm of Ribbert (1924), which arises by perforation of an ulcer of the valve cusp into a hollow thrombotic mass and by organization undergoes fibrosis of varying degree. Reports of such aneurysms are not infrequent in the early reports of bacterial endocarditis, but aneurysms having well-organized, smooth, fibrous walls are rare; Saphir and Leroy (1945) believe that some of them are true aneurysms resulting from the action of intra-ventricular pressure upon a portion of valve cusp weakened by valvulitis. The aneurysms affect the aortic valve more commonly than the mitral (Pelvet, 1867; Osler, 1908; Horder, 1909; von Arx, 1914; Soulié and Porge, 1937), and involve the anterior (aortic or right) cusp of the mitral valve much more often than the posterior. Habershon in 1855 described a smooth-walled aneurysm, $1.9 \mathrm{~cm}$. in diameter, affecting the aortic cusp of the mitral valve, and Ogle (1858 $a$ and $b$ ) described two smaller examples. Of the 23 cardiac valvular aneurysms collected by Pelvet, 9 affected the mitral valve. More recent instances of mitral valvular aneurysms are those of Horder (1909, Fig. 14), Calwell (1912), von Arx (1914), Whimster (1928), Pichon and Bidou (1932), Soulié and Porge (1937), Soulié et al. (1947), Saphir and Leroy (1948), Libman and Friedberg (1948), and Musallam and McCall (1953).

In this paper we report an extreme example of aneurysmal deformity of the mitral valve in a patient who survived for five years after an attack of subacute bacterial endocarditis treated with penicillin, and a further case that illustrates some aspects of the pathogenesis of the lesion.

\section{CASE REPORTS}

Case 1. This man was well until he developed subacute bacterial endocarditis at the age of 44 . Streptococcus viridans was isolated from his blood and he received 41 mega units of penicillin in the course of six weeks. At the time of admission to hospital, aortic incompetence was the dominant cardiac lesion, and although mitral murmurs were heard during his illness, the radiological appearances remained those of predominant aortic incompetence. He was discharged from hospital seven months later, and from this time onwards he was breathless on mild exertion; at the age of 46 , he began to have congestive cardiac failure. When he was admitted for the last time, aged 49, in gross failure, there was predominant mitral incompetence, moderate aortic incompetence, and some mitral stenosis.

Autopsy Findings. All organs showed evidence of advanced congestive heart failure, and there was a large recent infarct in the middle lobe of the right lung.

The heart weighed $770 \mathrm{~g}$. A large, slug-like thrombus was present on the postero-lateral wall of the right atrium. Both ventricles and the left atrium were dilated and hypertrophied. No recent vegetations were present on any part of the mural or valvular endocardium. The aortic valve was incompetent and possessed only two cusps, a posterior or non-coronary cusp and an anterior cusp in which a raphe of congenital type (Lewis and Grant, 1923; Koletsky, 1941) represented a rudimentary commissure between right and left coronary cusps. Both aortic cusps were large and thickened by fibrosis, but showed no nodularity. The mitral ring was dilated, admitting four fingers. The posterior cusp of the mitral valve appeared normal, but the anterior cusp was thickened by fibrosis which extended into the chordæ tendineæ of the anterior papillary muscle. From the anterior cusp an aneurysm, $4 \mathrm{~cm}$. in depth, projected through the mitral ring, into the left atrium (Fig. 1). The smooth wall of the sac was composed of fibrous tissue: three perforations, 


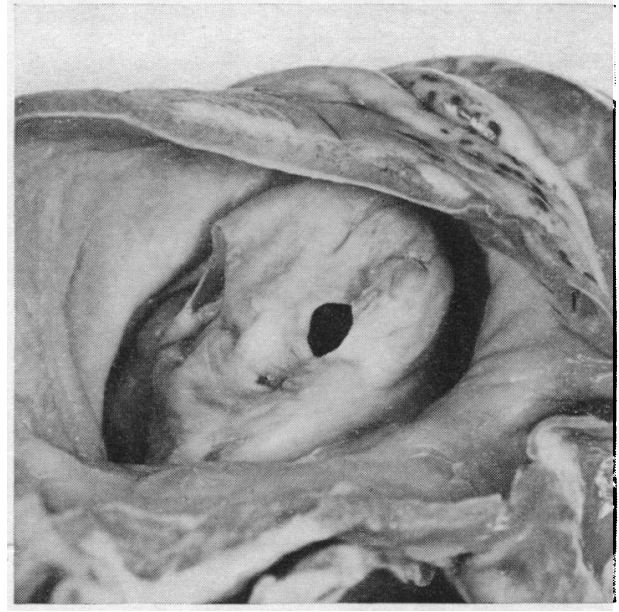

Fig. 1.-Case 1. Left atrium seen from above. Two perforations are seen in the wall of the aneurysm, which projects into the atrium.

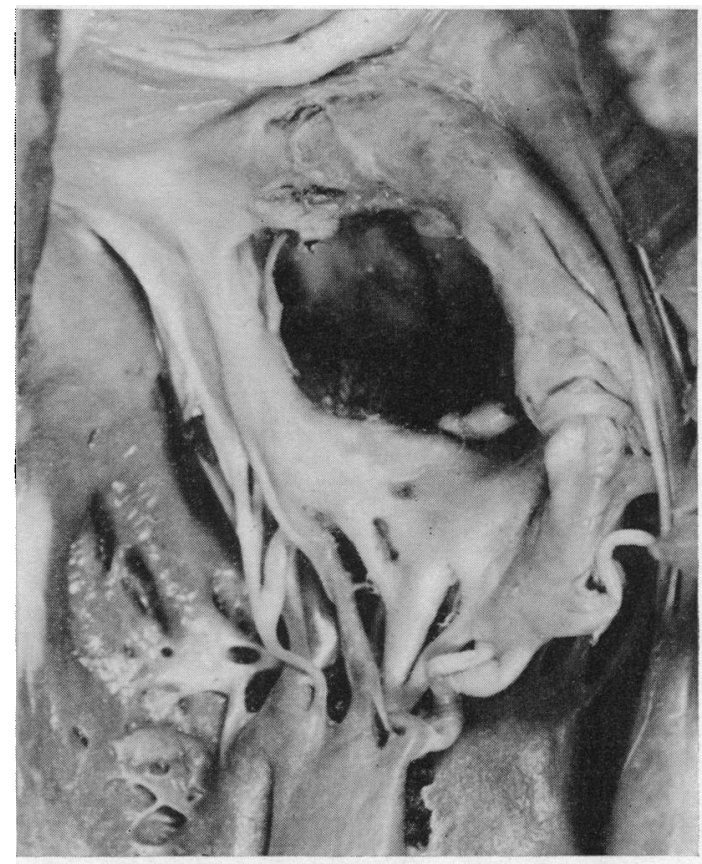

FIG. 2.-Case 1. A portion of the left ventricle, showing the orifice of the aneurysm of the anterior cusp of the mitral valve, and the patch of endocardial fibrosis on the upper part of the interventricular septum.

each $6 \mathrm{~mm}$. in diameter, were present, two in the dome of the aneurysm, and another in the posterior wall near its attachment to the valve cusp. The sac contained no thrombus. The orifice of the aneurysm (Fig. 2) measured $25 \mathrm{~mm}$. and $17 \mathrm{~mm}$. in transverse and antero-posterior diameters respectively, and its margins were thick and bordered by small calcified nodules, resembling healed vegetations. A patch of fibrous thickening, $12 \mathrm{~mm}$. by $4 \mathrm{~mm}$., was present on the endocardial surface of the upper posterior part of the interventricular septum, on its left ventricular aspect.

Case 2. The patient was discovered at the age of ten years to have pulmonary and mitral systolic murmurs, and a presystolic triple rhythm at the apex. He had no apparent cardiac disability, and no rheumatic history. For five years he continued to feel well: six weeks before death he complained of pain in the left loin. Subsequently he became breathless on exertion, and developed a cough. Just before admission he had attacks of vomiting and diarrhœa, with abdominal pain, and one small hæmoptysis.

On admission to hospital he was found to have a pulse rate of 160 a minute, a respiration rate of 48 a minute, and a normal temperature. He was tender in the right iliac fossa; no abnormality was found clinically in the heart and lungs, but radiological examination showed some cardiac enlargement and pulmonary œdema. He was thought to be suffering from a virus infection, and intravenous terramycin therapy was started, but he died suddenly a few hours later.

Autopsy Findings. The heart was dilated, and both ventricles showed hypertrophy. The tricuspid and pulmonary valves showed no significant abnormality but the aortic valve was bicuspid and slightly stenotic and incompetent. The posterior and the right coronary cusps were united, and there was a low median raphe on the floor of the cusp. The two aortic cusps, which will be referred to as the conjoined and left coronary cusps, were of similar size; their anterior portions were thickened by fibrosis and had slightly patulous and everted margins. A perforation $15 \times 5 \mathrm{~mm}$. was present in the conjoined cusp. Both aspects of the cusps were covered with small organizing but still partly friable vegetations, which were continuous with similar vegetations on the ventricular aspect of the base of the anterior cusp of the mitral valve. There they surrounded an orifice, $5 \mathrm{~mm}$. in diameter (Fig. 3): this opened into an aneurysm which measured $13 \mathrm{~mm}$. in diameter and projected into the left atrium (Fig. 4). The outer surface of the aneurysm was smooth except at the apex where a perforation, $5 \mathrm{~mm}$. in diameter, was encircled by partially organized vegetations. No abnormality was seen in the posterior cusp of the valve. 

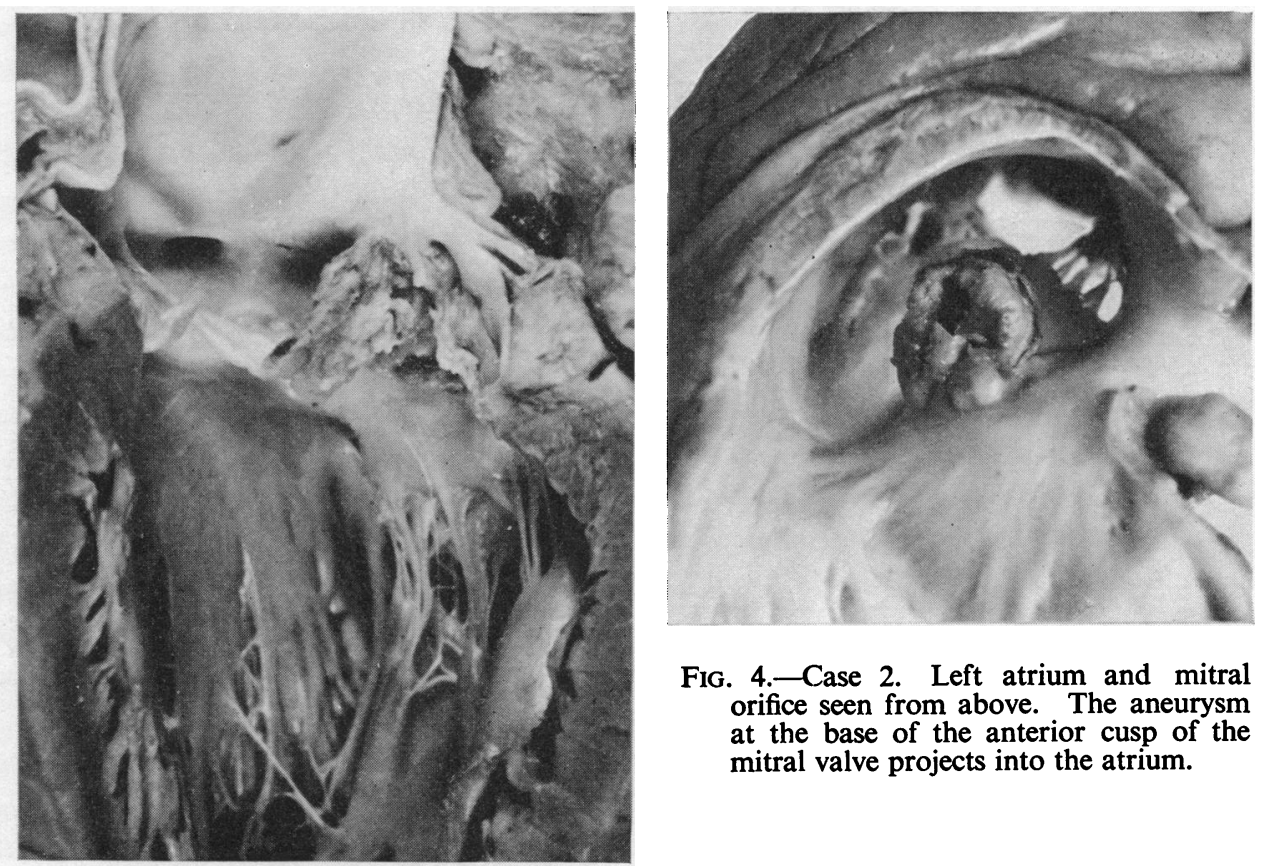

Fig. 4.-Case 2. Left atrium and mitral orifice seen from above. The aneurysm at the base of the anterior cusp of the mitral valve projects into the atrium.

FIG. 3.-Case 2. Left ventricle. Much of the left coronary cusp has been removed to display the orifice of the aneurysm of the anterior cusp of the mitral valve. The perforation of the conjoined cusp is hidden.

The other organs were congested: the spleen was enlarged to approximately twice normal size, and contained a pale infarct.

\section{Discussion}

Good descriptions of the gross appearances of the larger aneurysms of the mitral valve have been given by Rokitansky (1852) and more recently by Soulié and Porge (1937). The aneurysms are commonly situated near the base of the anterior cusp and project into the left atrium, but they may be situated nearer the free margin of the cusp and project into the ventricle. They measure up to $4 \mathrm{~cm}$. in diameter (Case 1), are commonly saccular, and have a wide orifice: the largest aneurysms show most organization. The sac may contain blood clot or thrombus.

Soulié and Porge believe that the aneurysms result from disease affecting primarily the aortic valve: they stress the almost invariable integrity of the posterior cusp of the mitral valve as indicating that former rheumatic endocarditis of the mitral valve plays little part in their pathogenesis. In their opinion, the elective localization of the aneurysms of the mitral valve is due to direct spread (" marche descendante") of bacterial endocarditis from the aortic valve to the ventricular aspect of the anterior cusp of the mitral valve. With this conclusion we are in broad agreement, although, of course, neither the aneurysms that are not associated with bacterial endocarditis (Musallam and McCall), nor those affecting the posterior mitral cusp can be explained in this way.

Localization of the bacterial infection might, however, be due also to impingement of a regurgitant stream from an incompetent aortic valve on the ventricular or valvular endocardium. Such a regurgitant stream in cases of uncomplicated aortic incompetence frequently causes localized thickening and pockets in the subaortic endocardium, which may become involved in bacterial endocarditis. In similar circumstances thickening may develop on the ventricular aspect of the 
anterior cusp of the mitral valve (Edwards et al., 1948). The incidence of aortic incompetence in cases of mitral valvular aneurysms is high, as is exemplified by the cases of von Arx, Soulié et al., Coulson (1850), Peacock (1851), Habershon, Calwell, Whimster, and Soulié and Porge. In this connection, cases of aortic incompetence in which the anterior mitral cusp was the sole site of bacterial vegetations are of particular interest: such are the cases described by Peacock, Calwell, and Horder (1906). In the museum of the Pathology Department of the University of Edinburgh there is a specimen (MB.2640) of pneumococcal endocarditis in a woman, aged 30, with a past history of rheumatic fever and clinical evidence of mitral stenosis: the mitral and aortic valves show postrheumatic fibrosis but only minute verrucous vegetations are present on the aortic and posterior mitral cusps. The ventricular aspect of the anterior cusp of the mitral valve, however, is extensively ulcerated and at a corresponding site on the opposite side of the cusp a polypoid thrombotic vegetation projects into the left atrium for a distance of $2 \mathrm{~cm}$.

In both of the cases reported here, the aortic valves were bicuspid. Such valves tend to become thickened and sclerosed (Paget, 1844; Koletsky) and as a result may become stenotic and incompetent (Smith and Matthews, 1955); also related, in all probability, to this tendency is their wellknown susceptibility to bacterial endocarditis. Our cases illustrate both points. In Case 1, aortic incompetence and left ventricular enlargement were well-established when the patient first came under observation with subacute bacterial endocarditis. In Case 2, cardiac murmurs were present five years before death, and the hypertrophy of the left ventricle indicated an aortic lesion of some duration.

Well organized aneurysms of substantial size can develop in the course of subacute bacterial endocarditis only if the disease is sufficiently prolonged to allow healing to accompany the ulcerative process. In untreated cases they are therefore more likely to be met with in the bacteria-free stage as mentioned by Libman and Friedberg than in an actively progressive phase of the disease. In patients treated with penicillin an increased incidence of aneurysms might be expected where valvular destruction was advanced before the therapy was instituted or where control of the disease was incomplete. Such was the experience of Saphir and Leroy, who attributed the high incidence of aneurysms in their later cases to penicillin therapy. It is apparent that this and other valvular distortions can be avoided only by early diagnosis. That adequate therapy alone may not be enough is demonstrated in Case 1 where the patient developed the largest aneurysm of the mitral valve yet recorded after surviving an attack of subacute bacterial endocarditis for five years.

\section{SUMMARY}

Two cases of aneurysm of the mitral valve are reported. One occurred in a patient with active, untreated subacute bacterial endocarditis. The other, the largest yet recorded, occurred in a patient who died in congestive cardiac failure five years after an attack of this disease treated by penicillin. In both instances the aortic valves were bicuspid.

The nature and pathogenesis of such aneurysms is discussed, and the importance of previous aortic valvular disease in these patients is stressed.

We are grateful to Professor G. L. Montgomery for helpful criticism, to Dr. R. M. Marquis for the history of Case 1, and to Dr. A. W. Wright and Mr. N. A. Gray for the clinical details of Case 2 . The illustrations are the work of the Photomicrography Unit of the University of Edinburgh.

\section{REFERENCES}

von Arx, W. (1914). Frankfurt Ztschr. Path., 15, 205.

Calwell, W. (1912). Brit. med. J., 2, 840.

Coulson, (1850). Trans. Path. Soc. Lond., 3, 77.

Edwards, J. E., Christensen, N. A., Clagett, O. J., and Macdonald, J. R. (1948). Proc. Mayo Clin., $23,324$.

Habershon (1855). Trans. Path. Soc. Lond., 6, 156.

Horder, T. J. (1906). Medico-Chirurg. Trans., 89, 333.

(1909). Quart. J. Med., 2, 289.

Koletsky, S. (1941). Arch. intern. Med., 67, 129 and 157. 
Lewis, T., and Grant, R. T. (1923). Heart, 10, 31.

Libman, E., and Friedberg, C. K. (1948). Subacute Bacterial Endocarditis., 2nd ed., Oxford University Press, New York.

Musallam, S. N., and McCall, M. (1954). Oklahoma State med. J., 47, 59.

Ogle, J. W. (1858 a). Trans. Path. Soc. London, 9, 117.

(1858 b). Trans. Path. Soc. London, 9, 131.

Osler, W. (1908). System of Medicine. Oxford Medical Publications, p. 137.

Paget, J. (1844). Med-Chir. Trans., 27, 162.

Peacock, T. B. (1851). Trans. Path. Soc. London, 3, 71.

Pelvet, N. Des Aneurysmes du Coeur. Thèse de Paris, 1867.

Pichon, E., and Bidou, S. (1932). Arch. Mal. Cour, 25, 296.

Ribbert, H. (1924). In: Henke, F., and Lubarsch, O. (eds). Handbuch der speziellen pathologischen Anatomie und Histologie. J. Springer, Berlin, 2, 184.

Rokitansky, C. (1852). A Manual af Pathological Anatomy. Sydenham Soc., London, 4, 236.

Saphir, O., and Leroy, E. P. (1948). Amer. J. Path., 24, 83.

Smith, D. E., and Matthews, M. B. (1955). Brit. Heart J., 17, 198.

Soulié, P., and Porge, J. (1937). Arch. Mal. Cour, 30, 491.

Soulié, Di Mattéo, and Bescol-Liversac (1947). Arch. Mal. Cour, 40, 472.

Whimster, W. S. (1928). Lancet, 2, 653. 